\title{
La complejidad de la gestión escolar en los CREI: un reto para directivos
}

\author{
Hilda Fernández García \\ Centro Chihuahuense de Estudios de Posgrado \\ hilda_fg@hotmail.com
}

\begin{abstract}
Resumen
El presente trabajo tiene como objeto aportar una descripción de la realidad que se vive en los Centros Regionales de Educación Integral (CREI). Para ello se toma como referencia dos estudios de caso, ambos ubicados en una localidad rural aledaña a la capital del estado. La intención, es dar cuenta de los procesos laborales que los directivos tienen que ejercer para liderar y operar un centro escolar con estas características. Se empleó el marco referencial interpretativo etnográfico (Álvarez-Gayou, 2003) para retratar la realidad cultural holística del grupo estudiado a través de la observación como método general. Las técnicas empleadas se realizaron en una primera fase con los registros de observación, las entrevistas a directivos y docentes y también se utilizó el grupo focal con maestros cocurriculares, empleados manuales y responsables de familia. A través del análisis de los datos obtenidos de los instrumentos permitieron evidenciar que los directores de los CREI enfrentan una ardua tarea ante las diversas actividades que implica la gestión escolar, de tal forma que emerge una nueva dimensión en la gestión escolar que practican los CREI: la dimensión política externa.
\end{abstract}

\section{Palabras clave}

Estudio de casos, gestión escolar, modelos educativos.

\section{Introducción}

La calidad educativa en México es un tema que toma relevancia a partir de la firma del Acuerdo Nacional para la Modernización de la Educación Básica en mayo de 1992 y el sistema educativo mexicano ha desplegado esfuerzos por mejorar los indicadores de pertinencia, eficiencia, eficacia y equidad en las escuelas del país. A pesar de estas medidas, actualmente se aprecia en el medio rural principalmente la falta de calidad por las condiciones existentes en las escuelas de este medio (multigrado), el contexto geográfico, socio-cultural y económico que las caracteriza. Como una estrategia para favorecer la calidad, el gobierno del estado de Chihuahua determina en su Plan Estatal de Educación 1999-2004 a través de la Secretaría de Educación y Cultura el programa denominado "Centros Regionales de Educación Integral” el cual se sustenta en DECRETO y REGLAMENTO aprobado por el $\mathrm{H}$. Congreso Local en el mes de abril del 2004.

Su objetivo es ofertar educación de CALIDAD a todos los alumnos chihuahuenses, independientemente de la zona geográfica del estado en que vivan para hacer de la EQUIDAD un compromiso del Estado para garantizar la igualdad en el acceso a las oportunidades. Todas las estrategias que implican la operatividad de los CREI se ven motivadas por la necesidad de transformar el ambiente educativo mediante una nueva Gestión 
Escolar que permita mejorar el proceso educativo, Pozner subraya que la gestión educativa:

Podemos definirla como un conjunto de acciones, relacionadas entre sí, que emprende el equipo directivo de una escuela para promover y facilitar la consecución de la intencionalidad pedagógica en-con-para la comunidad educativa (Pozner, 2005:70-71).

La gestión escolar que se vive en los CREI es un reto complejo que requiere de atención a una gran cantidad de aspectos como el sistema de organización y administración de la escuela, el análisis de plan y programas de estudio, métodos de enseñanza, programas compensatorios que permitan el acceso y la permanencia en el ámbito educativo, así como un trabajo arduo para fomentar la participación social. Esto obliga a las escuelas a adoptar una nueva forma de trabajo por la necesidad existente de transitar en una nueva gestión escolar con la finalidad de mejorar el proceso educativo.

Aunque el estudio contempla otras preguntas de investigación más amplias y de otros ámbitos, para el efecto del presente trabajo se exponen los hallazgos en torno a la pregunta: ¿Cómo se vive cotidianamente la gestión escolar en los CREI? Lo anterior con el objetivo de describir e interpretar la gestión escolar que se vive en los CREI.

Este estudio se posicionó en el paradigma cualitativo en el que, de acuerdo a Álvarez-Gayou (2003), plantea que la investigación cualitativa pretende y busca la subjetividad para comprender, interpretar y explicar la realidad, así como entender las interacciones $y$ los significados de los individuos y de los grupos sociales. Para explicitar el presente trabajo se hizo uso del marco referencial interpretativo etnográfico como camino para la búsqueda de la información. Los resultados que arroja la etnografía es el retrato de una realidad cultural holística del grupo estudiado, así como las interpretaciones y visiones del que investiga en relación a la vida social humana (Álvarez-Gayou, 2003).

Este estudio se basó en la observación como método, ya que no solamente se pone en práctica a la visión, sino todos los sentidos. Es considerada fundamentalmente descriptiva en un momento inicial, y conforme el investigador se adapta al grupo que se estudia, podrá contar con mayores posibilidades de descubrir, con mayor refinamiento, modelos o actividades que le facilitarán focalizar sobre todo su observación.

Para describir los hallazgos del presente estudio en función a la vida cotidiana que se gesta en los CREI, se organizó la información en categorías que emergieron del dato empírico para especificar las funciones que realizan los directivos de los CREI referidas a las cuatro dimensiones que de acuerdo a Pozner (2005) caracteriza el trabajo de la gestión escolar: pedagógica curricular, administrativa-financiera, comunitaria y de participación social y la dimensión organizativa-operativa, mismas que a continuación se especifican y se caracterizan sus rasgos a partir de situaciones observadas que se insertan en viñetas:

\section{La dimensión pedagógica-curricular}

Con lo que respecta a la función académica, el personal directivo debe lidiar con una gran cantidad de actividades como atender los grupos cuando los maestros titulares por alguna razón no asisten a la 
escuela y es muy normal que los directivos "cubran al grupo", es decir lo "atiendan":

Los atiende entre comillas porque sus funciones son muchos entonces él corre para acá y corre para allá va $\mathrm{y}$ les pone trabajo, los medio entretiene porque eso es en realidad lo que se hace. P21: Informante 1 CE TXT. -21:27

A la categoría que se le denominó "Función de supervisión: trabajo docente" tiene que ver con las visitas formativas a los grupos para verificar que el trabajo académico se lleve de acuerdo al currículo oficial:

Constantemente nosotros tenemos las visitas a los grupos, he estado muy pendiente de visitar los grupos en cuestión paso a hacer alguna pregunta o paso algo a observar, de esa manera yo observo cómo se está llevando, aparte de como los niños, estoy viendo el proceso en los niños. P25: Informante 5 CF.rtf 25:83

En este ámbito de acción se contempló todo lo referido al proceso áulico, lo que ocurre en el salón de clases, la relación de la enseñanza con el aprendizaje, así como los problemas que trae consigo este proceso.

\section{La dimensión administrativa- financiera}

Es un verdadero desafío para los directores manejar con éxito las actividades administrativas que la organización le demanda y los CREI no son la excepción. Para la administración del personal los directivos se enfrentan a una serie de dilemas a la hora que los directivos de tomar decisiones en la asignación de los grupos:

Se hace una distribución de grupos, entonces en base a esa distribución ya detectándose perfiles, detectándose lo que mejor convenga a los grupos, se establece, se designa el maestro para cada grupo. P25: Informante 5 CF.rtf 25:170.

Una característica que sobresale en los CREI tiene que ver con una responsabilidad "extra" que desempeña el director en cuanto a los recursos humanos se refiere:

Uno de los directivos aborda el problema político que se ha generado desde la creación de los CREI en el sentido que los presidentes municipales son quienes proponen al personal manual y de apoyo (maestros cocurriculares, choferes y coordinadora del comedor) contratado a través del convenio SEECH-Presidencia Municipal, en virtud que hacen compromisos de campaña y suelen cambiar a su antojo a este personal, ya que muchos de estos recursos humanos son despedidos sin consideración alguna, a pesar de su buen desempeño y sin tomar en cuenta la opinión del directivo, generando una gran inestabilidad en la calidad de los servicios que los nuevos recomendados ofrecen $\mathrm{y}$ por los que el directivo debe rendir cuentas a la sociedad. P14: Observación 14 CE.txt - 14:87

Los CREI son instituciones que manifiestan un comportamiento complejo en función de la gran cantidad de personas que la conforman. Esto complica en muchas ocasiones crear canales de información a fin de transmitirla a la base y mantener la estabilidad organizacional. A lo anterior se le denomina administración de la información y uso del tiempo. Las funciones de los directivos inician desde las 7:00 horas en que comienzan a salir los camiones y hasta las 
5 de la tarde que regresan los alumnos a sus respectivos destinos:

Lo de los autobuses es muy complicado maestra, conlleva mucha responsabilidad. Sí, es una gran responsabilidad esto que nosotros tenemos a cuestas, porque en caso de un accidente el único culpable de esto es el directivo, qué va pasar si pasa algún accidente. Cuando al chofer se le desbarata el camión, él hace una llamada de teléfono, lo único que trae es número de teléfono del celular para estar en contacto, pero también hay lugares en los que no tiene funcionalidad el celular y se batalla para contactarnos. La salida es a las 3 , pero nunca se da a las 3. P25: Informante 5 CF.rtf

Con lo que respecta sobre la información a la supervisión es una actividad muy demandada a los directivos de las escuelas, dado que, las cargas burocráticas que reciben son excesivas:

La directora sale apresuradamente a la supervisión escolar para entregar documentación. Al llegar a la supervisión escolar, el supervisor le comenta que la documentación no está completa. La directora regresa a la escuela para seguir llenando la documentación. Transcurre el tiempo, el supervisor decide suspender la revisión, en virtud de que son las 4:30 de la tarde. La directora se dispone a salir de la oficina y se dirige a su casa.

Con todas las actividades que de forma tan compleja atañen a los CREI, se requiere cierta habilidad para administrar el tiempo en las actividades cotidianas de la escuela:

Durante el día se atiende toda la problemática, no hay día que no haya un problema que resolver en el CREI, ya sea de tipo administrativo, económico, que es lo que más tenemos porque no acabalamos con nada: se nos acaba el gas y hay que salir corriendo a ver quién nos aporta para comprar el gas, que no llegaron las tortillas, que no ajustaron con el mandado que trajeron. No falta qué situación se presente durante la mañana, incluso hasta con las áreas de trabajo de los intendentes, pues no cubrió el área, viene el maestro me dice: --oiga no me hicieron aseo, que esté pendiente que los baños estén en buenas condiciones, que todo el día se les esté dando mantenimiento a esos baños. P25: Informante 5 CF.rtf - 25:300

Otro aspecto que cobra relevancia en las funciones que los directores desempeñan, es lo relacionado con la captación, manejo y destino de los recursos financieros. La presidencia municipal y la colaboración de los responsables de familia contribuyen de manera contundente para cubrir la mayoría de los gastos que generan estos centros escolares, ya que los CREI funcionan con la rigurosa asistencia de estas dos instancias.

\section{Dimensión comunitaria y de participación social}

En esta dimensión los directivos asumen un gran reto, ya que deben instituir un estrecho enlace desde la escuela hacia los responsables de familia, sociedad civil y política.

Una función más desempeñada por los directivos es concientizar a los padres sobre los beneficios que trae consigo su acercamiento a la escuela:

En asamblea general, el director les informa que en estos momentos se requiere de la presencia de los padres de familia en cada grupo con 
el maestro correspondiente para tratar asuntos relacionados con la forma de organización particular en cada uno de ellos. Los padres salen y se encaminan a cada uno de los salones de acuerdo al grado donde están inscritos sus hijos respectivamente. P15: Observación 15 CE.txt - 15:57

Se hace necesario pues, un proceso arduo de sensibilización por parte de los responsables de familia y personal de la escuela, de la necesidad mutua de colaboración.

La participación de la autoridad municipal en los Centros Regionales de Educación Integral (CREI) constituye un eslabón que fortalece la operatividad de estos centros educativos:

Presidencia municipal está cubriendo todas las necesidades del trasporte escolar como del plantel P34: Informante 6 CF.rtf 34:146 Presidencia se encarga de darle mantenimiento a los camiones, de ahí se paga el combustible, aceites, de todo lo relacionado a los autobuses. P22: Informante 2 CE.rtf - 22:97

\section{Dimensión organizativa-operativa}

Otro reto que tienen que asumir los directivos es lo relacionado con la dimensión organizativa- operativa que obliga a los directivos a ejercer una función que incida en todos los aspectos de la vida de la escuela.

En la organización del trabajo escolar se asume la forma, la cultura y los procesos de trabajo que se llevan a cabo en las organizaciones. En los Centros Regionales de Educación Integral se observa claramente este fenómeno de orden social-cultural en cuanto a la forma de cómo hacer las cosas que satisfacen los intereses del grupo, ya que se entreteje una diversidad de opiniones que deben ser tomadas en cuenta para lograr resultados significativos en su operatividad:

Se percibe la llegada de dos madres de familia y se acercan a la directora, una de ella la cuestiona sobre las rutas de los camiones, la otra con respecto a la inscripción de los alumnos. Se observa la llegada masiva de los alumnos acompañados por sus respectivas madres, así mismo se ve la entrada de los maestros que acuden con la directora para solicitar las llaves de sus respectivos salones. Las madres de familia siguen insistiendo para que la maestra les entregue los certificados y las boletas de los alumnos egresados en el ciclo escolar anterior. P 1: Observación 1 CF.txt

Estas acciones retratadas que surgen de una cotidianeidad invisible constituyen algunas de las numerosas funciones que los directivos de los CREI deben realizar y algunas de las reflexionen que emanan de ellas son:

Los directores de los CREI enfrentan una ardua tarea y las actividades de la gestión escolar se complejizan. Este contexto compromete y presiona la labor directiva la que incide directamente para el logro de una educación de calidad.

La figura directiva en los CREI tiene múltiples facetas de atención: docentes, alumnos, empleados especiales $\mathrm{y}$ manuales (intendentes, choferes, coordinadoras), autobuses, comedor escolar, responsables de familia, instancias oficiales y autoridades políticas. Los directivos de los CREI tienen que lidiar no solamente con cuestiones académicas y administrativas propias de su cargo, sino que tienen que afrontar situaciones de índole laboral que están fuera de su 
RECIE. Revista Electrónica Científica de Investigación Educativa Vol. 1, núm. 1, enero-diciembre 2012, pp. 113-119.

competencia profesional.

Tradicionalmente autores $y$ autoras de la gestión escolar como: Pozner (2005), el Programa Escuelas de Calidad de Balderrama (2006) y Romero (2008) establecen como dimensiones de la gestión escolar: la pedagógica-curricular, misma que tiene que ver con los fines y objetivos específicos que se propone una institución escolar en el ámbito del aula o salón de clases y todo lo que ocurre dentro de ella. La Comunitaria que enlaza las relaciones entre la comunidad local y la escuela; la sociedad civil y política. La administrativa-financiera que refiere a la máxima optimización de los recursos humanos y financieros del centro escolar. La organizativa- operativa que constituye el soporte de las demás dimensiones que al articularse se pretende lograr el funcionamiento integral, consciente $y$ participativo del centro escolar.

Lo anterior demuestra que ninguno de los autores y autoras antes mencionados abordan la complicada relación entre la escuela con las presidencias municipales, en tanto esta tesis es una investigación inacabada, ya que la teoría no alcanza a cubrir situaciones como las que a continuación se presentan:

En el caso de los trabajadores que laboran en los CREI: maestros especiales: (inglés y computación), empleados manuales (choferes, intendentes y coordinadoras de los comedores) que son propuestos y nombrados por las presidencias municipales. Se advierten frecuentemente casos de cambios $y$ despidos injustificados por estas instancias. Lo anterior tiende a complejizar la estructura organizacional de la escuela. Esto porque así lo determinan ellos, ya sea por intereses políticos como es el caso de las promesas de campaña o por intereses personales y/o familiares.

Este tipo de acciones involucran directamente a los directivos, ya que no se les pide opinión para realizar este tipo de movimientos, pero sí recae en ellos la responsabilidad de asumirlas, mismas a las que deben enfrentar, así sea de orden legal o personal:

Esto significa que cada tres años se cuenta con personal nuevo y no nada más en ese tiempo, sino cada vez que el presidente así lo decide y esto ahorita nos está causando un grave problema. Porque uno de los choferes fue despedido, anteriormente había un acuerdo entre la secretaría de Educación y Cultura (SEC) o más bien la coordinación CREI y los padres de familia, que ellos se iban a encargar del traslado de los alumnos, pero se les consiguió una pequeña compensación. Uno de los choferes, recibía su compensación y la recibió por tres años, al entrar el nuevo presidente municipal lo despide $y$ trae su gente. P25: Informante 5. CF. rtf.-25:254

Estas circunstancias sitúan a los directivos en una disyuntiva bastante compleja e incómoda porque a las "primeras de cambio" despiden a personas responsables que desempeñan sus funciones cabalmente $y$ crean una inestabilidad moral y emocional en los directivos:

Los presidentes municipales suelen cambiar a su antojo a este personal, ya que muchos de estos recursos humanos son despedidos sin consideración alguna, a pesar de su buen desempeño y sin tomar en cuenta la opinión del directivo. P14: Observación 14 CE.txt - 14:87 
A través de esta mirada se puede apreciar que el directivo tiene que lidiar, no solamente con cuestiones académicas y administrativas propias de su cargo, sino que tiene que afrontar situaciones de índole laboral que están fuera de su competencia profesional.

Por lo antes planteado y para interpretar la gestión escolar de los CREI introduzco la dimensión política externa que vincula la relación de las presidencias municipales con la escuela, centrada en la comunicación y el diálogo para establecer un clima armónico laboral que propicie la estabilidad de la organización escolar.

\section{Referencias}

Álvarez-Gayou, J. (2003). Cómo hacer investigación cualitativa. Fundamentos y metodología. México, D.F.: Paidós. Pp.222.

Balderrama, S. (2006). ¡Al Grano! Con el Plan Estratégico de Transformación Escolar. SEC. Gobierno del Estado de Chihuahua. PEC. Chihuahua, México. Pp. 192.

Fullan, Michael. Hargreaves, Andy. (2000). La escuela que queremos, los objetivos por los que vale la pena luchar. Ed. Imprentor S.A. de C.V. México. Pp. 191.

GOBIERNO DEL ESTADO DE CHIHUAHUA (2003). Decreto 624/03 VII P. E., que declara de interés social y de carácter permanente el "Programa para el establecimiento y operación de los Centros Regionales de Educación Integral del Estado de Chihuahua". Periódico Oficial, Chihuahua, México.

Loera Varela, A (2000). Los grupos de enfoque en la investigación educativa. En Romelia Hinojosa. (2007). Antología de Modalidades de la Investigación Chihuahua: Centro Chihuahuense de Estudios de Posgrado. Pp. 169

Pozner de Weinberg, Pilar (2005). El Directivo como gestor de aprendizajes escolares. Buenos Aires: Aique Grupo Editor. pp. 7175.

Romero, Claudia. (2008), Hacer de una escuela, una buena escuela. Evaluación y mejora de la gestión escolar. Buenos Aires, Aiqué.

Taylor, S.J.; Bogdan, R. (1984). Introducción a los métodos cualitativos de investigación. En Romelia Luján (Comp.). Antología Taller de Investigación II. Modalidades de la Investigación (2007). Centro Chihuahuense de Estudios de Posgrado. Chihuahua. Pp. 16. 
RECIE. Revista Electrónica Científica de Investigación Educativa

Vol. 1, núm. 1, enero-diciembre 2012, pp. 113-119.

Fernández García, H. 